\title{
OUTROS ESPAÇOS EXPOSITIVOS ${ }^{1}$
}

Regina Melim²

Palavras Chaves: espaço portátil, publicação-exposição, circulação, participação.

Resumo : O texto discute sobre um tipo particular de dispositivo curatorial cujo objetivo é expandir a noção de espaço expositivo e, por conseguinte, a própria noção de exposição. Trata-se da proposição de mostras que são realizadas no espaço de uma publicação, caracterizando-se como um espaço portátil, que expande o circuito dos espaços institucionais de museus e galerias, extrapolam o meio físico de uma sala expositiva, bem como, suas fronteiras geográficas.

Reconhecido como informação primária, a publicação converte-se ela própria na exposição, alterando profundamente a forma convencional de recepção, uma vez que espectador não apenas leva consigo, mas passa a interagir tactilmente com as obras artísticas que ali se inserem.

Como exemplificação e aprofundamento destas questões que emergem destes outros espaços expositivos, apresentamos duas exposições-publicações e um desdobramento: pf (por fazer) e sua forma desdobrada, to be done, organizada em 2006 e, amor.love: leve com você.take with you, organizada em 2007. Como uma estrutura portátil, oferecida a todo visitante da exposição, estas proposições acontecem no espaço expositivo de um museu ou galeria, através de uma permanência temporária e com o mínimo de recurso ou sofisticação de montagem.

\section{[ OUTROS ESPAÇOS EXPOSITIVOS ]}

O texto debate sobre um tipo particular de dispositivo curatorial, denominado Exposições Portáteis, cujo objetivo é conjugar a reflexão e a prática de estratégias de curadoria e modos de circular um trabalho artístico. Como reflexão sobre estes procedimentos, parte-se da noção de difusão e circulação como forma de construção de novos circuitos e que estes, na medida do possível, possam também extrapolar as paredes de um espaço físico de um museu ou galeria.

${ }^{1}$ Artigo organizado a partir do Projeto de Pesquisa "Exposições Portáteis".

${ }^{2}$ Prof. Dra. Departamento de Artes Plásticas CEART-UDESC.

DAPesquisa, Florianópolis, v.2, n.4, p. 253-262, 2007. 
Seu formato portátil (ou de bolso) prevê como modelo de apresentação, pequenas publicações: livro, blocos ou folhas avulsas em embalagens, contendo desenhos e textos na forma de proposições ou instruções. De baixo custo, estas publicações possuem o objetivo expresso de alargar o espectro de audiência e participação, através de tiragens impressas, ilimitadas para reprodução. Além disso, a publicação como espaço expositivo, torna-se o dispositivo que prolonga a efemeridade do tempo de uma exposição, deslocando o que sempre se vinculou como informação secundária ou registro de uma exposição realizada em espaços de museus e/ou galerias para, ela própria - a publicação - ser o veículo primário das práticas artísticas que ali se inserem.

Uma tentativa, também, de vislumbrar uma exposição como deflagradora de um contínuo movimento participativo, existindo não como estrutura pronta, fechada em si, mas como uma superfície aberta e distributiva. E em permanente circulação, alterando profundamente a forma convencional de recepção, uma vez que espectador não apenas leva consigo a exposição, mas passa a interagir tactilmente com a obra artística.

A distribuição ou a dispersão, sem dúvida, tem nos interessado sobremaneira. Pensamos que é a partir dela que podemos ampliar esta participação e criar novos circuitos. Circuitos que vão além dos espaços circunscritos de museus e galerias, a partir de um espaço portátil, que uma vez acessado, poderá ser transportado para a realização de uma obra em qualquer lugar, a qualquer hora, em diferentes contextos. Como um objeto transportável, uma espécie de estrutura de inspeção ${ }^{3}$ oferecida à participação.

Este interesse por difusão e circulação de obras, conduzindo à formação de novos circuitos, extrapolando o meio físico de uma sala expositiva, trazem à tona alguns questionamentos do sistema da arte como um todo. Partes integradoras deste sistema, composto especialmente por artista, curador e espectador, podem se apresentar envolvidas de tal forma, que se vêem em um dado momento ampliadas e/ou deslocadas de suas funções.

De posse destas proposições, vislumbradas desde o início como deflagradoras de um contínuo movimento participativo, estas partes tendem a não se apresentarem mais isoladas. Como um conjunto - condição essencial para o desenvolvimento desta proposição - surgem em forma de binômios: espectador-participador, artista-propositor, artistacurador, participador-curador e quantas combinações possíveis dentro deste sistema, que desde o princípio tem como objetivo se apresentar como uma estrutura agenciadora e intercambiável ${ }^{4}$.

\footnotetext{
${ }^{3}$ Tomo de empréstimo o termo estruturas de inspeção que era a denominação que Helio Oiticica atribuía aos seus Bólides, objetos que eram dados à manipulação e uso do espectador e, a partir daí, transformarem-se em espaços poéticos tácteis.

${ }^{4}$ Esta estrutura agenciadora e intercambiável parte de conceitos e idéias apresentadas pelo artista Ricardo Basbaum quando propõe os termos artista-etc/curador-etc como aquele que questiona a natureza e a função

DAPesquisa, Florianópolis, v.2, n.4, p. 253-262, 2007.
} 
Para discutir e aprofundar questões que emergem desses outros espaços expositivos, apresentamos duas exposições-publicações e um desdobramento: pf (por fazer), e sua forma desdobrada: to be done, e amor.love: leve com você.take with you.

A primeira destas exposições - denominada pela sigla pf, como forma abreviada do codinome inicial intitulado por fazer, apresentava as obras como proposições, ou como instruções, cuja realizações se dariam a partir de uma participação. Desenvolvida na Universidade, suas primeiras anotações aconteceram ainda em 2005 e contou com a participação de alunos da graduação ${ }^{5}$ e da pós-graduação ${ }^{6}$, e de uma série de $\operatorname{artistas}^{7}$ convidados no decorrer do processo construtivo desta proposição.

$\mathrm{Na}$ sua origem, surgia como possibilidade de pensar a noção de Performance nas artes visuais tentando substituir o estereótipo, quase sempre associado sob um único formato - o artista em uma ação ao vivo, assistido por uma audiência, num tempo e espaço específico - para um viés bem mais distendido. E incluir, então, não somente ações que ocorrem ao vivo, mais uma série de outros trabalhos (remanescentes ou não), que pudessem estabelecer uma definição possível para Performance nas artes visuais, contemplando trabalhos cujos elementos são performativos. Associado a esta noção, portanto, incluiríamos dentre uma variante de procedimentos, uma produção de textos e desenhos, marcadamente com características de instruções. Interessava-nos naquele momento, a partir desta distensão do conceito, pensar uma noção de Performance realizada pelo espectador que, em posse destas instruções, poderia interpretá-las e realizá-las. Teríamos ainda a possibilidade da criação de um espaço relacional, (que na elaboração deste projeto surgia sob a denominação de espaço de performação ${ }^{8}$ ),

de seu papel, promovendo trânsitos entre as partes componedoras do sistema da arte e fora dela, a partir de híbridos que se instauram e questionam em novas combinações, tais como: artista-curador, artista-professor, artista-ativista, curador-artista, curador-diretor, curador-engenheiro, curador-produtor, entre outros.

${ }^{5}$ Participantes da Oficina de desenvolvimento: O espaço como configuração de um campo específico (semestre 2005/2) e Oficina avançada: Processos, mediações e ampliações do corpo na arte contemporânea (semestre 2006/1), ambas ministradas para o curso de Licenciatura e Bacharelado em Artes Plásticas.

${ }^{6}$ Participantes da Disciplina eletiva: Incorporações - agenciamentos do corpo no espaço relacional (semestre 2006/2), ministrada no Programa de Pós Graduação em Artes Visuais - Mestrado.

${ }^{7}$ Foram convidados 12 artistas brasileiros (Alex Cabral (PR), Ana Paula Lima (SP), Daniela Mattos (RJ), Jorge Menna Barreto (SP), Julia Amaral (SC), Laercio Redondo (PR), Melissa Barbery (PA), Nara Milioli (SC), Orlando Manescky (PA), Raquel Stolf (SC), Ricardo Basbaum (RJ), Yiftah Peled (SC)) e a artista mexicana Minerva Cuevas, na época como artista residente aqui no país, participante da $27^{\mathrm{a}}$. Bienal Internacional de São Paulo.

${ }^{8}$ Espaço de performação entende-se como sendo o espaço que surge do encontro do espectador com a obraproposição, possibilitando a criação de uma estrutura relacional ou comunicacional. Ou seja, o espaço de ação

DAPesquisa, Florianópolis, v.2, n.4, p. 253-262, 2007. 
significando um maior grau de participação, uma vez que cada espectador levaria consigo uma matriz geradora de outros tantos espaços de performação.

Do material recebido, que reunia 36 participantes, o projeto foi elaborado como um bloco de notas, seguindo a lógica de emissão de faturas em que temos folhas duplas destacáveis correspondendo, respectivamente, o original e a cópia. Todavia, restava ainda outra discussão que seria: como expor, veicular e colocar em circulação esta exposiçãopublicação?

Imaginamos, então, que como uma estrutura portátil, oferecida a todo visitante, seu formato de exposição poderia acontecer no espaço expositivo de um museu ou galeria, a partir de uma permanência temporária e com o mínimo de recurso ou sofisticação de montagem. Um tipo de dispositivo curatorial, dentro desta perspectiva de mobilidade e circulação, que incluísse o menor número de equipamento possível, todavia, o suficiente para que pudéssemos, com cada mostra, não somente distribuir os bloquinhos, mas também pensar no conjunto de sua apresentação e recepção.

Sugeriu-se, então, como equipamento curatorial necessário, apenas uma parede (para que pudéssemos dispor as folhas expostas lado a lado), uma mesa (para colocar as pilhas de blocos que estariam à disposição do público), e cadeiras (para que pudéssemos nos reunir em grupos e debater sobre o projeto, estendendo sua participação, ampliando seus níveis de reflexão).

Como desdobramento desta exposição-publicação, apresentamos uma versão para a Internet, denominada to be done ${ }^{9}$, lançada no projeto Draw_drawing_2, mostra que integrava a Bienal de Londres, no período de 4 a 9 de julho de 2006. Na forma de índice, (uma página onde continha todas as proposições da versão impressa), planejamos para o espaço expositivo apenas um computador e uma impressora. 0 espectador então poderia visualizar cada um dessas instruções-obra, ampliando-a na tela, imprimindo-a, enviando-a para o seu arquivo pessoal ou para alguém. 0 'objeto' passava a ser de sua propriedade uma vez que, na qualidade de participador, deixando de ser uma testemunha imparcial e se colocando em ação, poderia estar realizando algumas destas instruções.

A segunda Exposição Portátil, organizada em 2007, foi denominada de amor.love: leve com você.take with you e contou com a participação de 60 artistas (igualmente, entre

do espectador, estendendo portanto a noção de Performance como um procedimento que se prolonga também no participador.

${ }^{9}$ Disponível no site: www.terreno.baldio.nom.br 
alunos da graduação ${ }^{10}$, pós-graduação ${ }^{11}$ e convidados $^{12}$ ). 0 tema reuniu proposições diversas que, conforme indicava o sub-título, objetivava sua circulação.

No formato de um livrinho de bolso, da mesma forma que o projeto anterior requisitava um equipamento para viabilizar sua distribuição. Seguindo a mesma lógica do menor número de equipamento possível, sugeriu-se novamente uma parede (desta vez, para colocar o texto de apresentação do projeto), uma prateleira (para colocar uma quantidade definida de livrinhos, que seriam repostos de acordo com a necessidade) e, igualmente, cadeira (para encontro e debates).

[ Referências.Aderências ]

Estas dinâmicas apresentadas nestas publicações que se objetivam como exposição, ocupando temporariamente espaços expositivos de museus ou galerias, e com recursos mínimos, enquanto proposições curatoriais tem na sua base uma série de referências históricas extraídas, grade parte delas, da década de 60. Uma delas, e que tem nos acompanhado durante todo o projeto são as ações curatoriais empreendidas pelo jovem galerista, marchand e editor, Seth Siegelaub. Para ele, publicações significavam a mesma coisa que um espaço de galeria significa para a maioria das pessoas. Documento e obra, reprodução e obra se equivaliam e a publicação passava a ser um dispositivo que estabelecia novas estratégias curatoriais.

$\mathrm{Na}$ organização de exposições como, January Show (1969), Seth Siegelaub desloca procedimentos usuais estabelecidos no sistema de arte, invertendo a relação usual entre o trabalho exposto e o Catálogo. Dispondo de algumas obras em espaços alugados, afirmava que o verdadeiro espaço da exposição era o Catálogo. Que a presença física dos objetos dispostos nos espaços físicos era suplementar à publicação, tornando-a, portanto, informação primária e não mais secundária. Ou seja, interessava pensar obras como informação, que podia circular e através de um meio constituído não somente por objetos,

\footnotetext{
"Participantes da Oficina avançada: Processos, mediações e ampliações do corpo na arte contemporânea (semestre 2006/1).

${ }^{11}$ Participantes do Seminário Temático: Relações Obra-Espaço, Circuitos e Sistemas (semestre 2006/1).

${ }^{12}$ Alexandre Antunes (RS), Alex Cabral (PR), Aline Dias (SC), Ana Miguel (RJ), Ana Paula Lima (SP), Brígida Baltar (RJ), Bruno Machado (PR), Carla Zaccagnini (SP), Carlos Asp (SC), Clevenson Salvaro (PR), Daniel Acosta (RS), Daniel Horsch (SP), Daniela Mattos (RJ), Dennis Radüns (SC), Diego Raick (SC), Eliane Prolik (PR), Glaucis de Moraes (RS), Jose Rafael Mamigonian (SC), Jorge Menna Barreto (SP), Julia Amaral (SC), Laércio Redondo (PR), Lucia Koch (SP), Lucio Agra (SP), Luiz Rodolfo Annes (PR), Maikel de Maia (PR), Marcos Chaves (RJ), Mariana Silva da Silva (RS), Melissa Barbery (PA), Milton Machado (RJ), Nara Milioli (SC), Nazareno Rodrigues (SP), Nicolás Varchausky (AR), Orlando Manescky (PA), Paulo Bruscky (PE), Raquel Garbelotti (ES), Raquel Stolf (SC), Ricardo Basbaum (RJ), Rimon Guimarães (PR), Rodrigo Garcia Lopes (PR), Roseline Ranoch (Al), Sergio Basbaum (SP), Suely Fahry (RJ), Tatiana Ferraz (SP), Teresa Riccardi (AR), Yara Guasque (SC), Yiftah Peled (SC).
}

DAPesquisa, Florianópolis, v.2, n.4, p. 253-262, 2007. 
mas também através de textos, desenhos e/ou fotografias.

Em Xerox Book (1968), outra exposição-publicação, Seth Siegelaub legitima este formato de exposição utilizando e enfatizando o meio de reprodução como estratégia critica à unicidade e autenticidade de uma obra de arte. A reprodução em série utilizava o formato semelhante àquele utilizado pelo artista Mel Bochner, em 1966, quando realiza a exposição Working Drawings and other visible things on paper not necessarily meant to be viewed as Art (Desenhos de trabalhos e outras coisas visíveis sobre papel não necessariamente feitas para serem encaradas como obras de arte), na School of Visual Art, NY, reproduzindo através de xerox uma série de trabalhos de artistas convidados a participarem da mostra.

Embora sabemos que Xerox Book não foi fotocopiado integramente (dado o alto custo que isto significava na época), pois apenas sua matriz era em xerox, o projeto sinalizava a reprodução como meio constitutivo da exposição e dos trabalhos que ali se inseriam. Meio que alargava profundamente a audiência de uma obra, alterando a forma convencional de distribuição e recepção de um trabalho artístico. Confirmando, ainda, e reforçando o que Walter Benjamin já havia anunciado em seu texto $A$ obra de arte na era de sua reprodutibilidade técnica sobre a perda da aura, a obra varrida da concepção de objeto único. Estabelecendo a publicação como lugar possível para a produção e exposição, acentuava e inaugurava uma forma expandida de pensar a obra de arte. A partir de experiências como estas, afirmava Siegelaub, seria quase impossível imaginar a noção de obra a partir de uma autoria individual, porque através deste acesso, a exposição ou cada um dos trabalhos individualmente, passariam a ser de todos imediatamente.

Outra referência que também se tornou imediata à esta noção de Exposição Portátil aqui proposta, foi o projeto Do It (1994), coordenado pelo curador Hans Ulrich-Obrist. Sua estruturação conceitual estabelecia-se na tática de remoção da mão do artista, formulada por Marcel Duchamp, conferindo às instruções dos artistas participantes do projeto o estatuto de obra-proposição. Do It tomava também de empréstimo as estratégias estabelecidas nas instruções de John Cage em suas (a)notações musicais, bem como, as formulações de alguns de seus alunos como, George Brecht, Jackson Mac Low, Allan Kaprow, Dick Higgins ${ }^{13}$, entre outros. Da mesma forma, partia ainda de referências extraídas dos cartões-eventos do Grupo Fluxus; das licenças para que outros executassem o trabalho, de Yoko Ono; da produção de objetos dos minimalistas, a partir de desenhos esquemáticos, como Sol LeWitt, Donald Judd, Robert Morris e Dan Flavin; além de toda a série de trabalhos de artistas integrantes da arte conceitual.

\footnotetext{
${ }^{13} \hat{E}$ interessante destacar aqui que Dick Higgins, artista integrante do Fluxus, manteve durante parte dos anos 60 e 70 uma editora própria, destinada à publicação de seus 'experimentos', bem como de diferentes artistas daquele período: Something Else Press e, posteriormente, nos anos 70, Unpublished Editions.
}

DAPesquisa, Florianópolis, v.2, n.4, p. 253-262, 2007. 
Do It, conforme assinalava Hans Ulrich-Obrist, havia sido pensado e concebido como um modo de exposição que deveria ajudar a desafiar as regras que geralmente governam a circulação de mostras de arte contemporânea. Desenvolvendo-se como uma exposição que não deveria aniquilar diferenças e reduzir a complexidade para um produto, mas sim aumentar diferenças e complexidade, e propor novas 'temporalidades'.

Curadores, organizadores e artistas participantes deste projeto, salientava ainda Obrist, buscam neste projeto construir uma temporalidade diferenciada, que resiste ao tempo formatado da cultura de exposição, que se estabelece através da fórmula: começou-acabou. E que quando desmanchada, tudo é novamente pintado de branco. E ainda, estendida no tempo e dispersa nos mais distintos espaços que circula, Do It implementava de forma mais efetiva a participação, através de uma versão dita domicilar, que em forma de livro, de um programa de televisão e de um website, apresentaria instruções feitas especificamente para 'uso doméstico' ${ }^{14}$.

Importante também para este projeto de Exposições Portáteis, que aqui estamos apresentamos, foi a proposição Point D'Ironie, idealizada pelos artistas Christian Boltanski e Bertrand Lavier e pelo curador Hans Ulrich-Obrist. Coordenado desde 1994 por este último, Point D'Ironie aposta na distribuição em larga escala (em torno de 100.000 exemplares) que são dispersos em diferentes locais e países: museus, galerias, cafés, cinemas, escolas, correio, lojas de departamentos (sobretudo Agnès b que é quem mantém o projeto financeiramente), entre outros tantos espaços.

No decorrer desta pesquisa, outras referências tem sido aderidas, agregando outros autores e propositores de outros formatos e espaços de exposição, inserindo-se como potenciais propulsores de uma reflexão mais aprofundada sobre a noção de Exposição Portátil.

Um dois quais temos acessado com certa freqüência tem sido Alexander Alberro, sobretudo, seu livro Conceptual Art and the politics of publicity, onde detecta, a partir de estudos críticos da Arte Conceitual, o aparecimento de estratégias por ele nomeadas como 'publicitárias'. Elegendo como exemplificações as exposições de Seth Siegelaub em Revistas, Jornais e Catálogos, e as proposições de Joseph Kosuth, no codinome Arthur Rrose - na função de critico, galerista, editor e teórico - Alberro traça uma trajetória do período que envolve meados dos anos 60 à década de 70. Período em que os artistas buscaram novos meios, matérias e lugares para expor suas ações artísticas, via de regra,

\footnotetext{
${ }^{14}$ O projeto Do It iniciou em 1994 com uma série de exposições com obras-instruções, realizadas em diferentes locais, em diferentes paises. Dez anos depois, o projeto ganha a versão dita domiciliar, reunindo uma gama considerável destas participações. Em formato livro ou na web (www.e-flux) podemos acessar a qualquer momento e realizar qualquer uma das instruções ali contidas.
} 
composta muito mais por idéias do que por objetos, sinalizados de forma magistral por Lucy Lippard em seu livro-índice: Six Years: The dematerialization of the art object from 1966 to 1972.

Optando pelo viés de uma análise destes procedimentos a partir da Arte Conceitual, Alexander Alberro e Blake Stimson no livro, Conceptual Art: a critical anthology, apresentam uma seleção de textos, igualmente pontuais para a pesquisa, composto por depoimentos de diferentes artistas e críticos sobre o período de 1966-77. Uma revisão necessária para que possamos analisar uma série de procedimentos atuais, dada à sua ressonância, e que nos endereça a outro estudo recentemente organizado por Alexander Alberro e Sabeth Buchmann, Art after conceptual art.

Em Art after conceptual art a paródia à Joseph Kosuth em seu texto Art after philosophy é explícita e marca toda a conceituação da séries de ensaios apresentadas por diferentes autores, que abordam não apenas o legado da Arte Conceitual para as décadas que thes são posteriores, mas localizam, em diferentes estudos de casos, como a atualidade daqueles procedimentos ainda são mantidos. Dos textos reunidos nesta compilação, Helmut Draxler em Letting Loos(e) - Institutional Critique and design tem nos interessado sobremaneira. Não apenas pelo inteligente jogo de palavras postas no título: ('deixando') Loos(e) ('livre') referindo-se a Adolf Loos e seu interesse em defender a funcionalidade no design em oposição à decoração e superficialidade, e face à isto, apresentar uma análise da proposição artística de Louise Lawer para o espaço de uma caixa de fósforos. 0 texto de Helmut Draxler e a proposição de Louise Lawer são claros em afirmar que o surgimento de outros circuitos (como estes aqui descritos), trazem junto de si também uma postura crítica frente às instituições e sistemas vigentes.

Neste sentido, Douglas Crimp surge como referência primordial para analisar estes contextos, deslocamentos e novas direções como ação crítica frente às instituições. Acompanhado por Louise Lawer em seu livro, Sobre as Ruínas do museu, este autor sublinha em todas as suas avaliações, o quanto o 'mundo de fora' cada vez mais é aderido aos procedimentos artísticos, re-afirmando a cada nova postura formulada pelos artistas, que a autonomia da arte é uma ficção, uma construção do museu. Nos anos 60 em diante, prossegue Crimp, as manifestações artísticas esgotaram os recursos dos museus. Não financeiramente, mas física e ideologicamente através de desafiadores atentos, como Marcel Broodthaers, Hans Haacke e Louise Lawer, apenas para citar alguns dentre outros tantos.

Douglas Crimp ainda nos apresenta e analisa alguns processos artísticos que surgem evitando o museus. Não porque estes jamais o exibiriam, mas porque, construídos no interior de uma outra lógica (ideológica, perceptiva e construtiva), todos estes

DAPesquisa, Florianópolis, v.2, n.4, p. 253-262, 2007. 
procedimentos existem para acontecerem fora do perímetro destas instituições.

\section{] [ Fora e dentro do Perímetro Institucional ] [}

Refletir sobre as práticas curatoriais apresentadas aqui nesta pesquisa, implica buscar outros valores e enfoques, outras formas e maneiras de analisar uma atividade artística e, principalmente, outros modos de expor e veicular. Trata-se, portanto, não de propor procedimentos que 'evitariam' o museu, mas propor conjunções que possam construir e se expandir em novos circuitos. Que o museu possa abarcá-las e difundi-las, possibilitando à construção de novos formatos de exposição.

As estruturas portáteis pf (por fazer), to be done e amor.love leve com você.take with you são aqui propostas como espaços de experimentação, que podem se desenvolver nos mais distintos lugares. O museu é um deles.

Os trabalhos que ali se inserem existem como potência deflagradora de um movimento participativo, criador contínuo de um espaço de ação do espectador, afirmando que uma proposição artística possui muitas maneiras de se constituir/construir, bem como, de apontar estratégias de ampliação e criação de novos circuitos. E desta forma, poder estar, igualmente, fora e dentro do perímetro institucional.

[ Referências Bibliográficas ]

ALBERRO, Alexander. Recording Conceptual Art: early interviews with Barry, Huebler, Kaltenbach, LeWitt, Morris, Oppenhein, Siegelaub, Smithson and Weiner by Patrícia Norvell. Cambridge: MIT Press, 2001.

Conceptual Art and the politics of publicity. Cambridge: MIT

Press, 2003.

BASBAUM, Ricardo. Amo os Artistas-etc In: MOURA, Rodrigo (org). Políticas Institucionais,

Práticas Curatoriais. Belo Horizonte: Museu da Pampulha, 2004, pp. 21-23.

BATTCOCK, Gregory . La idea como arte. Documentos sobre el arte conceptual.

Barcelona: Gustavo Gili, 1977.

DAPesquisa, Florianópolis, v.2, n.4, p. 253-262, 2007. 
BOCHNER, Mel. Mel Bochner. RJ: Centro de Arte Helio Oiticica, 1999.

BURY, Stephen. The book as a work of art, 1963-1995. England: Scolar Press, 1995.

GODFREY, Tony. Conceptual Art. London: Phaidon Press, 1998.

LAUF, Cornelia and PHILLPOT, Clive. Artist/Author: Contemporary Artist's Books. New York: American Federation of Arts/Weatherspoon Art Gallery, 1998.

LIPPARD, Lucy. Six years: the desmaterialization of the Art Object from 1966 to 1972. Berkeley, 1997.

OBRIST, Hans Ulrich. Do It. New York/Frankfurt: e-flux/Revolver, 2004.

OSBORNE, Peter. Conceptual Art. London: Phaidon, 2002.

WOOD, Paul. Arte Conceitual. SP: Cosac \& Naify, 2002.

www.e-flux

www.pointdironie.com 